\title{
Research on the Design and Modification of Asymmetric Spur Gear
}

\author{
Xiaohe Deng, Lin Hua, and Xinghui Han \\ School of Automotive Engineering, Hubei Key Laboratory of Advanced Technology of Automotive Parts, \\ Wuhan University of Technology, Wuhan 430070, China
}

Correspondence should be addressed to Lin Hua; lhua@whut.edu.cn

Received 9 June 2014; Accepted 17 October 2014

Academic Editor: Davide Spinello

Copyright (c) 2015 Xiaohe Deng et al. This is an open access article distributed under the Creative Commons Attribution License, which permits unrestricted use, distribution, and reproduction in any medium, provided the original work is properly cited.

A design method for the geometric shape and modification of asymmetric spur gear was proposed, in which the geometric shape and modification of the gear can be obtained directly according to the rack-cutter profile. In the geometric design process of the gear, a rack-cutter with different pressure angles and fillet radius in the driving side and coast side was selected, and the generated asymmetric spur gear profiles also had different pressure angles and fillets accordingly. In the modification design of the gear, the pressure angle modification of rack-cutter was conducted firstly and then the corresponding modified involute gear profile was obtained. The geometric model of spur gears was developed using computer-aided design, and the meshing process was analyzed using finite element simulation method. Furthermore, the transmission error and load sharing ratio of unmodified and modified asymmetric spur gears were investigated. Research results showed that the proposed gear design method was feasible and desired spur gear can be obtained through one time rapid machining by the method. Asymmetric spur gear with better transmission characteristic can be obtained via involute modification.

\section{Introduction}

Gear drives are one of the most widely used modes in power transmission system with the advantages of large power, high efficiency, and long service life. The involute tooth profile has various advantages, such as good transmission performance, convenient installation, and low cost $[1,2]$. Compared with traditional involute spur gears, asymmetric involute gears have larger carrying capacity, smaller volume, lighter weight, and better dynamic characteristics [3]. So the asymmetric spur gear has significant potential applications in the fields of heavy load and high-speed gear transmission system. In the gear transmission process, it is not possible to have the mating gear enter contact in pure involute position because there would be sudden interference corresponding to the elastic deflection and the corner of the tooth tip would gouge into the mating surface [1]. Real meshing tooth profile of asymmetric spur gears will deviate from the ideal location under load and will cause transmission error and the change of load distribution. The transmission error changes over time, which causes displacement excitation in the gear dynamic model and has great influence on the dynamics of meshing gears [4-6]. Therefore, it is necessary to improve the meshing performance of asymmetric spur gears by the reasonable design and modification.

Until now, many researches have been carried out on the design and modification of symmetric gear. Litvin et al. [7] proposed a modified involute helical gear that matches with a double-crowned pinion and simulated the meshing process between profile-crowned and double-crowned helicoids. Faggioni et al. [8] presented a global optimization method that focused on reducing gear vibration by means of profile modifications. Barbieri et al. [9] used genetic algorithms to research the optimum profile. Zhang et al. [10] performed computer-aided design based on the contact conditions of conjugated gears and the tooth end relief with helix by finite element analysis (FEA). Gonzalez-Perez et al. [11] applied analytical approach in the stress analysis for gear drive with localized bearing contact based on the Hertz theory. Huang and $\mathrm{Su}$ [12] presented various approaches about element constructions and dynamic analyses for involute spur/helical gears where meshed elements are constructed 
directly without CAD geometric model. The gear profile equations were described via $\mathrm{C}$ programming language. The effects of modification coefficients and helical angles on the transient meshing performance of the gears were investigated using the method of explicit dynamic FEA from the perspective of energy by $\mathrm{Hu}$ et al. [13]. A qualitative analysis about the effects of flank deviation on load distribution for helical gear was performed using FEM by Wei et al. [14]. Wu et al. [15] proposed a tooth profile modification approach for the helical pairs, and the static contact process was analyzed using FEA and experimental tests. Li [16] applied 3D FEM to conduct surface contact stress and root bending stress calculations for a pair of spur gears considering machining errors, assembly errors, and tooth modifications. Simon [17] researched on the influence of tooth modifications induced by machine tool setting and head-cutter profile variations on tooth contact characteristics in face-hobbed spiral bevel gears. Chen and Shao [18] proposed a general analytical meshing stiffness model to establish the relationship between the gear tooth errors and the total mesh stiffness, wherein load sharing among different tooth pairs during meshing and static transmission errors under load were considered. Sankar and Nataraj [19] proposed a modification design approach for increasing the tooth strength in spur gear. Wang et al. [20] proposed a method to simulate residual stress field of planetary gear. Li and Kahraman [21] proposed a tridynamics model for spur gear pairs. The proposed model couples a mixed elastohydrodynamic lubrication model of a spur gear pair with a transverse torsional dynamic model. Kolivand and Kahraman [22] defined new general concept based on the construction of a surface of roll angle to simplify the task of locating instantaneous contact lines of any type of gearing. With the surface of roll angle defined, instantaneous contact lines are determined by a novel approach based on an analogy to parallel-axes gears. Eritenel and Parker [23] provided an analytical solution for the nonlinear vibration of gear pairs that exhibit partial and total contact loss.

Moreover, more and more attention has been paid to asymmetric gear recently. Litvin et al. [3] proposed the modified geometric model of an asymmetric spur gear drive which integrated an involute gear and a double crowned pinion and simulated the meshing and contact process of the spur gears with proposed geometric parameters using computer-aided design method. Alipiev [24] proposed a new geometric design method for the symmetric and asymmetric involute meshing in which the gear load sharing ratio is equal to its expected value. Pedersen [25] observed the use of two new standard cutting tools for the asymmetric gears since the shape of the gear profile influences its bending strength.

In the gear design process, the traditional method only gives basic parameters of gear structure and it is difficult to obtain precise model for the actual generated gear. In this paper, the equations of gear tooth profile were deduced based on a given rack-cutter, and the accurate geometric model was established in the design process. In the traditional machining process of modified gear, a standard gear without modification is generated at first, and the modification is conducted subsequently. In order to enhance the manufacturing efficiency, the pressure angle modification is carried out on

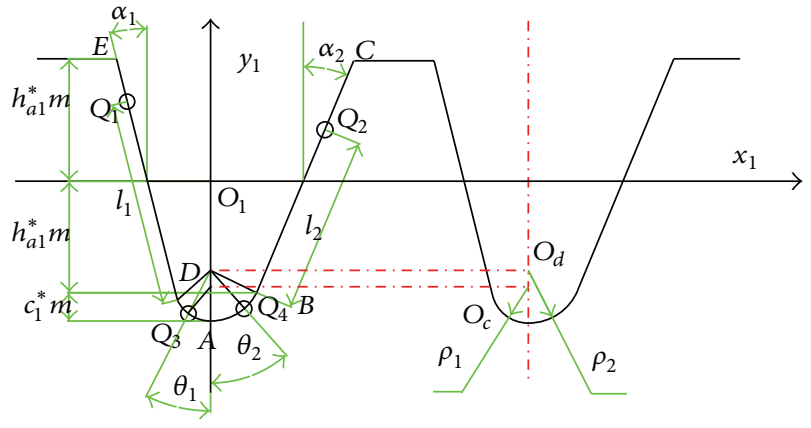

FIGURE 1: Gear rack-cutter normal profile and tool coordinate system.

the rack-cutter, so the desired modified spur gear can be obtained through one time rapid machining.

Based on the proposed gear design and modification method, a FEM of asymmetric involute gear was established where computer-aided designs were adopted to establish the geometry model of the spur gears; finally the meshing process was simulated.

The present paper mainly consists of the following three aspects.

(1) The equations of a new rack-cutter profile for asymmetric gear were established. The pressure angle modification in rack-cutter design was proposed and the driving side of rack-cutter profile equations was deduced. The given rack-cutter profile has different pressure angles and fillet radius in the driving side and coast side. The generated asymmetric spur gear profiles have different pressure angles and fillets accordingly (Section 2).

(2) According to conjugate theory, the equation of asymmetric spur gear was derived by the forming rackcutter tool. Computer-aided design of spur gears with proposed geometric parameters and the simulation of their meshing were conducted using the proposed methods (Section 3).

(3) The transmission error and the load sharing ratio of generated gears were studied. The transmission principles of asymmetric spur gear were discussed (Section 4).

\section{Geometric Characteristics of the Rack-Cutter Profile}

In order to obtain the precise gear model, the geometric characteristic of the corresponding rack-cutter profile is required. The given rack-cutter has different pressure angles and fillet radius in the driving side and coast side.

2.1. The Rack-Cutter Normal Profile. The typical rack-cutter consists of straight lines and tip circular fillet, which can generate involutes and fillets of typical involute tooth, respectively. As depicted in Figure 1, the tool coordinate system $S_{1}$ is rigidly fixed to the gear rack-cutter, and the coordinate axis 
$x_{1}$ is the reference line of rack-cutter. The basic normal profile of rack-cutter consists of four segments: driving side flank straight line $B C$, coast side flank straight line $D E$, driving side flank tip fillet curve $A B$, and coast side flank tip fillet curve $A D$. The gear tool possesses different gradients on either side of the rack-cutter straight tooth profile and has the same addendum coefficient and tip clearance coefficient. The profile of the rack-cutter in $S_{1}$ can be described with the following equations.

(i) Coast side flank straight line $D E$ is

$$
\begin{aligned}
& x_{1}=-l_{1} \sin \alpha_{1}-\rho_{1} \cos \alpha_{1}, \\
& y_{1}=l_{1} \cos \alpha_{1}-h_{a 1}^{*} m, \\
& 0 \leq l_{1} \leq \frac{2 h_{a 1}^{*} m}{\cos \alpha_{1}},
\end{aligned}
$$

where $Q_{1}$ is an arbitrary point on line $D E, l_{1}$ is a variable parameter about the length of straight line $D Q_{1}, \alpha_{1}$ is the pressure angle representing the slope of line $D E, \rho_{1}$ is the radius of fillet curve $A D, h_{a 1}^{*}$ is the addendum coefficient factor, and $m$ is the normal module.

(ii) Driving side flank straight line $B C$ is

$$
\begin{aligned}
& x_{1}=l_{2} \sin \alpha_{2}+\rho_{2} \cos \alpha_{2}, \\
& y_{1}=l_{2} \cos \alpha_{2}-h_{a 1}^{*} m, \\
& 0 \leq l_{2} \leq \frac{2 h_{a 1}^{*} m}{\cos \alpha_{2}},
\end{aligned}
$$

where point $Q_{2}$ is an arbitrary point on line $B C, l_{2}$ is the variable parameter about the length of straight line $B Q_{2}, \alpha_{2}$ is the pressure angle representing the slope of line $B C$, and $\rho_{2}$ is the radius of fillet curve $A B$.

(iii) Coast side flank cutter fillet curve $A D$ is

$$
\begin{aligned}
x_{1} & =-\rho_{1} \sin \theta_{1}, \\
y_{1} & =-\rho_{1}\left(\cos \theta_{1}-\sin \alpha_{1}\right)-h_{a 1}^{*} m, \\
0 & \leq \theta_{1} \leq \frac{\pi}{2}-\alpha_{1},
\end{aligned}
$$

where $\theta_{1}$ is the angle of ${ }_{A} O_{c} Q_{3}$ and $Q_{3}$ is an arbitrary point on the fillet curve $A D$.

(iv) Driving side flank rack-cutter fillet curve $A B$ is

$$
\begin{aligned}
x_{1} & =\rho_{2} \sin \theta_{2}, \\
y_{1} & =-\rho_{2}\left(\cos \theta_{2}-\sin \alpha_{2}\right)-h_{a 1}^{*} m, \\
0 & \leq \theta_{2} \leq \frac{\pi}{2}-\alpha_{2},
\end{aligned}
$$

where $\theta_{2}$ is the angle of ${ }_{A} O_{c} Q_{4}$ and $Q_{4}$ is an arbitrary point on the fillet curve $A B$.

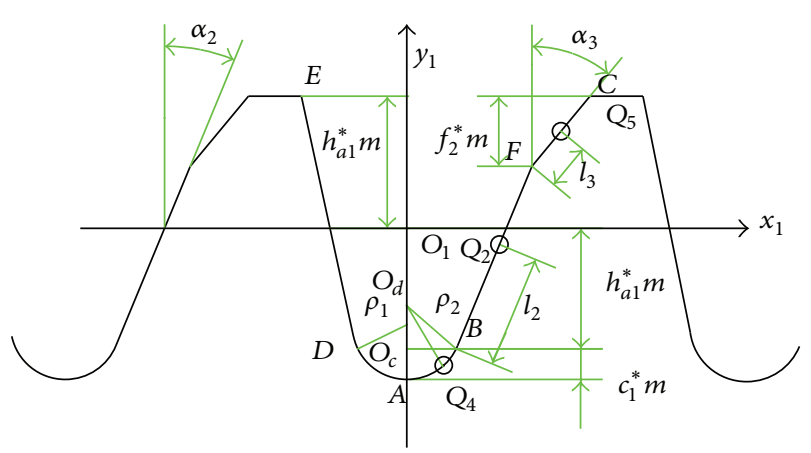

FIGURE 2: Gear rack-cutter normal profile with pressure angle modification.

The radii of fillet curve $\rho_{1}$ and $\rho_{2}$ meet

$$
\begin{aligned}
& \rho_{1}=\frac{c_{1}^{*} m}{\left(1-\sin \alpha_{1}\right)}, \\
& \rho_{2}=\frac{c_{1}^{*} m}{\left(1-\sin \alpha_{2}\right)},
\end{aligned}
$$

where $c_{1}^{*}$ is the tip clearance coefficient.

The tangential vector $\vec{t}$ to the generated shape in the $S_{1}$ is

$$
\vec{t}=\frac{d x_{1}}{d v} \overrightarrow{i_{1}}+\frac{d y_{1}}{d v} \overrightarrow{j_{1}}
$$

The unit normal vector in $S_{1}$ is

$$
\overrightarrow{n_{n}}=\frac{t \times \overrightarrow{k_{1}}}{\left|t \times \overrightarrow{k_{1}}\right|}, \quad \overrightarrow{k_{1}}=\left[\begin{array}{lll}
0 & 0 & 1
\end{array}\right] .
$$

The unit normal vectors of each profile in $S_{1}$ can be derived as

$$
\begin{array}{ll}
\overrightarrow{n_{n-D E}}=\left[\begin{array}{c}
\cos \alpha_{1} \\
-\sin \alpha_{1} \\
0
\end{array}\right], & \overrightarrow{n_{n-B C}}=\left[\begin{array}{c}
-\cos \alpha_{2} \\
-\sin \alpha_{2} \\
0
\end{array}\right], \\
\overrightarrow{n_{n-A D}}=\left[\begin{array}{c}
-\sin \theta_{1} \\
-\cos \theta_{1} \\
0
\end{array}\right], & \overrightarrow{n_{n-A B}}=\left[\begin{array}{c}
\sin \theta_{2} \\
-\cos \theta_{2} \\
0
\end{array}\right],
\end{array}
$$

where the subscripts $D E, B C, A D$, and $A B$ represent the corresponding line and curves.

2.2. The Equations of Pressure Angle Modification. The conventional design of asymmetric spur gear is based on the application of involute profiles [1]. If the lines in the tool tip have different slopes, the generated gear will be modified correspondingly. Thus the driving side of rack-cutter will have two pressure angles, and the generated gear will have two segments of involute profile on the driving side. It is easy and feasible to produce such a rack-cutter.

The pressure angle modification can be represented by two parameters in the tool coordinate: the modified angle $\alpha_{3}$ and the modified length $f_{2}^{*} m$, as shown in Figure 2. The 


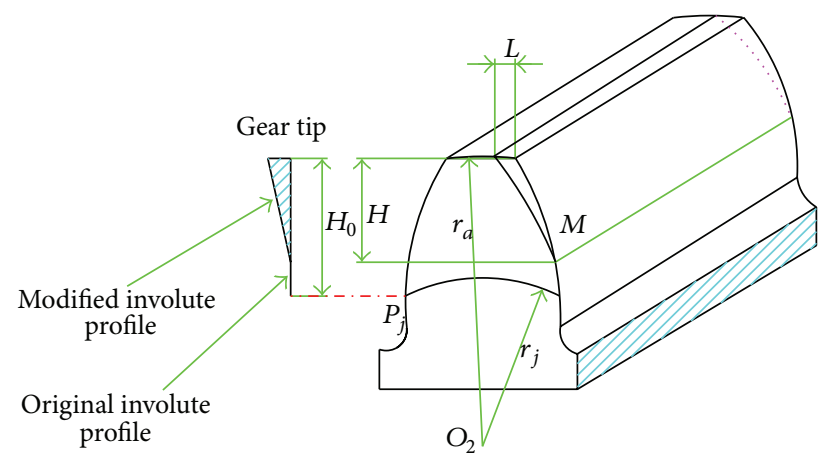

FIGURE 3: Schematic diagram of a single tooth profile.

parameter $f_{2}^{*}$ is called modified coefficient. The modified new gear profiles are shown in Figure 3. $L$ is the maximum modified quantity; $H$ is the maximum modified length. $H$ is the distance between the modified point $M$ and the gear tip, which should be within the range of $0 \sim \mathrm{H}_{0}$.

The equations of modified tool profiles are listed as follows.

(i) Driving side flank straight line $B F$ is

$$
\begin{aligned}
& x_{1}=l_{2} \sin \alpha_{2}+\rho_{2} \cos \alpha_{2}, \\
& y_{1}=l_{2} \cos \alpha_{2}-h_{a 1}^{*} m, \\
& 0 \leq l_{2} \leq \frac{2 h_{a 1}^{*} m-f_{2}^{*} m}{\cos \alpha_{2}},
\end{aligned}
$$

where $f_{2}^{*}$ is the modification coefficient; $\alpha_{3}$ is the pressure angle after modification.

The unit normal vector $\overrightarrow{n_{n \_B F}}$ of line $B F$ meets

$$
\overrightarrow{n_{n \_B F}}=\left[\begin{array}{c}
-\cos \alpha_{2} \\
-\sin \alpha_{2} \\
0
\end{array}\right] \text {. }
$$

(ii) Driving side flank straight line FC is

$$
\begin{aligned}
& x_{1}=l_{3} \sin \alpha_{3}+\rho_{2} \cos \alpha_{2}+\frac{h_{a 1}^{*} m}{\sin \alpha_{2}}, \\
& y_{1}=l_{3} \cos \alpha_{3}+h_{a 1}^{*} m-f_{2}^{*} m, \\
& 0 \leq l_{3} \leq \frac{h_{a 1}^{*} m-f_{2}^{*} m}{\cos \alpha_{3}} .
\end{aligned}
$$

The unit normal vector $\overrightarrow{n_{n F C}}$ of line FC meets

$$
\overrightarrow{n_{n F C}}=\left[\begin{array}{c}
-\cos \alpha_{3} \\
-\sin \alpha_{3} \\
0
\end{array}\right] \text {. }
$$

\section{The Gear Profiles Equations}

The gear profile equation is the foundation of the parameter modeling. Due to the application of coordinate transformation, we can deduce the generated gear profiles from the equation of rack-cutter profile based on the kinematic relation and

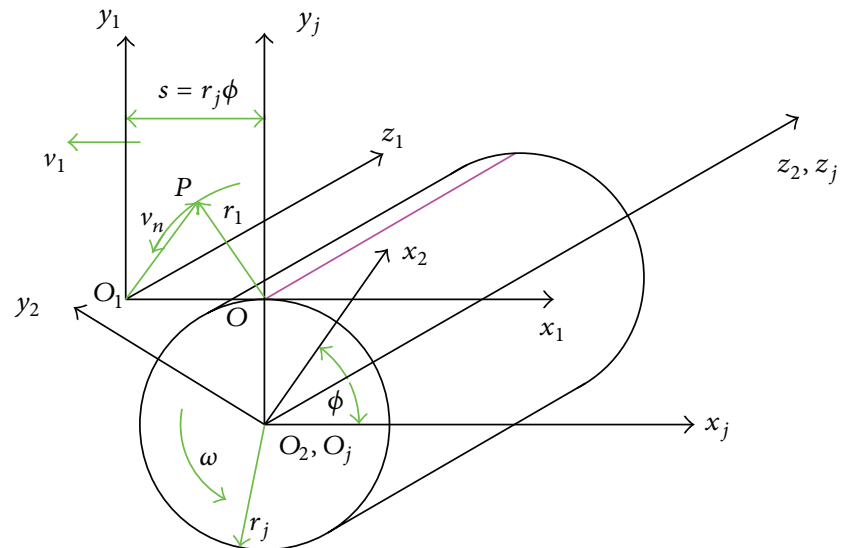

FIGURE 4: Coordination systems transformations.

conjugate theory. After the pressure angle modification of rack-cutter, the generated gear will be modified with involute curve.

3.1. The Coordinate Transformation. Coordinate systems $S_{1}$, $S_{2}$, and $S_{j}$ were rigidly fixed to the rack-cutter, the spur gear to be generated, and the frame (see Figure 4) [7]. A point $N$ in coordinate system $S_{2}$ was represented by position vector $\overline{\mathrm{O}_{2} \mathrm{~N}}=\overrightarrow{r_{2}}$. A vector in coordinate system $S_{1}$ was signed as $\vec{r}_{1} . \phi$ is the rotate angle of gear blank. The coordinate transformation from $S_{1}$ to $S_{2}$ was based on the matrix equation

$$
\overrightarrow{r_{2}}=M_{21} \overrightarrow{r_{1}} \text {. }
$$

The transformation matrix $M_{21}$ can be determined by

$$
M_{21}=\left[\begin{array}{cccc}
\cos \phi & \sin \phi & 0 & r_{j}(\sin \phi-\phi \cos \phi) \\
-\sin \phi & \cos \phi & 0 & r_{j}(\cos \phi+\phi \sin \phi) \\
0 & 0 & 1 & 0
\end{array}\right] .
$$

In this way, we can obtain the equation of gear profile from that of rack-cutter profile as follows:

$$
\begin{gathered}
x_{2}=x_{1} \cos \phi+y_{1} \sin \phi+r_{j}(\sin \phi-\phi \cos \phi), \\
y_{2}=-x_{1} \sin \phi+y_{1} \cos \phi+r_{j}(\cos \phi+\phi \sin \phi) .
\end{gathered}
$$

3.2. Meshing Equations. Suppose that the rack moves at a velocity of $\overrightarrow{v_{1}}$ and the gear rotates at an angular velocity of $\vec{\omega}$ (Figure 4). The instantaneous center of rotation $O$ is located on line $\mathrm{O}_{2} \mathrm{O}$ that is perpendicular to $\overrightarrow{v_{1}}$. The location of $\mathrm{O}$ satisfies the vector equation

$$
\overrightarrow{v_{1}}=\vec{\omega} \times \overrightarrow{\mathrm{O}_{2} \mathrm{O}}
$$

The relative motion of centrode is pure rolling around $O$ and the displacements of rack and the rotate angle of gear blank $\phi$ can be correlated by

$$
s=r_{j} \phi
$$

where $r_{j}$ is the pitch circle of gear. 
The vector radius of a moving point $P$ in coordinates $S_{1}$ is

$$
\overrightarrow{r_{1}}=x_{1} \overrightarrow{i_{1}}+y_{1} \overrightarrow{j_{1}}
$$

The sliding velocity at point $P$ is

$$
\overrightarrow{v_{n}}=\overrightarrow{v_{1}}-\overrightarrow{v_{2}},
$$

where $\overrightarrow{v_{2}}$ is the velocity of point $P$ in coordinates $S_{2}$ given by

$$
\overrightarrow{v_{2}}=\vec{\omega} \times \overrightarrow{r_{1}}+\overrightarrow{O_{1} O_{2}} \times \vec{\omega},
$$

where

$$
\begin{aligned}
\overrightarrow{v_{1}} & =-v_{1} \overrightarrow{i_{1}}=-\omega r_{1} \overrightarrow{i_{1}}, \\
\vec{\omega} & =\omega \overrightarrow{k_{1}}, \\
\overrightarrow{O_{1} O_{2}} & =r_{j} \phi \overrightarrow{i_{1}}-r_{j} \overrightarrow{j_{1}} .
\end{aligned}
$$

From (8) through (20), we can derive

$$
\overrightarrow{v_{n}}=\omega\left[y_{1} \overrightarrow{i_{1}}+\left(r_{j} \phi-x_{1}\right) \overrightarrow{j_{1}}\right] .
$$

Any meshing point $P$ on the gear tooth profile needs to meet the following conditions: the relative motion velocity vector of the point should be located in a common tangent of the two tooth profiles along a direction; namely,

$$
\vec{\varphi}=\overrightarrow{n_{n}} \cdot \overrightarrow{v_{n}}=\overrightarrow{0}
$$

where $\overrightarrow{n_{n}}$ is the unit normal vector of meshing point (equation (8)) and $\overrightarrow{v_{n}}$ is the relative velocity vector.

According to the normal vector of different line segments and the relative velocity in (23), meshing equation can be obtained by

$$
\begin{aligned}
& D E: x_{1} \sin \alpha_{1}+y_{1} \cos \alpha_{1}-r_{j} \phi \sin \alpha_{1}=0, \\
& B C: x_{1} \sin \alpha_{2}-y_{1} \cos \alpha_{2}-r_{j} \phi \sin \alpha_{2}=0, \\
& A D: x_{1} \cos \theta_{1}-y_{1} \sin \theta_{1}-r_{j} \phi \sin \theta_{1}=0, \\
& A B: x_{1} \cos \theta_{2}+y_{1} \sin \theta_{2}-r_{j} \phi \sin \theta_{2}=0 .
\end{aligned}
$$

3.3. Conjugate Gear Profile Equations. The tooth shape of the generated gear without modification is represented by (15) and (24). Each segment of gear profile curves is listed as follows.

(i) Coast side flank involute gear profile is

$$
\begin{gathered}
x_{2}=x_{1} \cos \phi+y_{1} \sin \phi+r_{j}(\sin \phi-\phi \cos \phi), \\
y_{2}=-x_{1} \sin \phi+y_{1} \cos \phi+r_{j}(\cos \phi+\phi \sin \phi), \\
x_{1} \sin \alpha_{1}+y_{1} \cos \alpha_{1}-r_{j} \phi \sin \alpha_{1}=0 .
\end{gathered}
$$

(ii) Driving side flank involute gear profile is

$$
\begin{gathered}
x_{2}=x_{1} \cos \phi+y_{1} \sin \phi+r_{j}(\sin \phi-\phi \cos \phi), \\
y_{2}=-x_{1} \sin \phi+y_{1} \cos \phi+r_{j}(\cos \phi+\phi \sin \phi), \\
x_{1} \sin \alpha_{2}-y_{1} \cos \alpha_{2}-r_{j} \phi \sin \alpha_{2}=0 .
\end{gathered}
$$

(iii) Coast side flank gear fillet curve is

$$
\begin{aligned}
& x_{2}=x_{1} \cos \phi+y_{1} \sin \phi+r_{j}(\sin \phi-\phi \cos \phi), \\
& y_{2}=-x_{1} \sin \phi+y_{1} \cos \phi+r_{j}(\cos \phi+\phi \sin \phi),
\end{aligned}
$$

$$
x_{1} \cos \theta_{1}-y_{1} \sin \theta_{1}-r_{j} \phi \sin \theta_{1}=0 \text {. }
$$

(iv) Driving side flank gear fillet curve is

$$
\begin{gathered}
x_{2}=x_{1} \cos \phi+y_{1} \sin \phi+r_{j}(\sin \phi-\phi \cos \phi), \\
y_{2}=-x_{1} \sin \phi+y_{1} \cos \phi+r_{j}(\cos \phi+\phi \sin \phi), \\
x_{1} \cos \theta_{2}+y_{1} \sin \theta_{2}-r_{j} \phi \sin \theta_{2}=0 .
\end{gathered}
$$

We can deduce the general equation of asymmetric involute gears profile with double pressure angles in $S_{2}$ from (1)-(4) and (25)-(28) as follows.

(i) Coast side flank involute gear profile is

$$
\begin{aligned}
x_{2}= & \left(-l_{1} \sin \alpha_{1}-\rho_{1} \cos \alpha_{1}-r_{j} \phi\right) \cos \phi \\
& +\left(l_{1} \cos \alpha_{1}-h_{a 1}^{*} m+r_{j}\right) \sin \phi, \\
y_{2}= & \left(l_{1} \sin \alpha_{1}+\rho_{1} \cos \alpha_{1}+r_{j} \phi\right) \sin \phi \\
& +\left(l_{1} \cos \alpha_{1}-h_{a 1}^{*} m+r_{j}\right) \cos \phi, \\
\phi= & -\frac{\left(l_{1}+\rho_{1} \cos \alpha_{1} \sin \alpha_{1}-h_{a 1}^{*} m \cos \alpha_{1}\right)}{\left(r_{j} \sin \alpha_{1}\right)}, \\
0 \leq & l_{1} \leq \frac{2 h_{a 1}^{*} m}{\cos \alpha_{1}} .
\end{aligned}
$$

(ii) Driving side flank involute gear profile is

$$
\begin{aligned}
x_{2}= & \left(l_{2} \sin \alpha_{2}+\rho_{2} \cos \alpha_{2}-r_{j} \phi\right) \cos \phi \\
& +\left(l_{2} \cos \alpha_{2}-h_{a 1}^{*} m+r_{j}\right) \sin \phi, \\
y_{2}= & -\left(l_{2} \sin \alpha_{2}+\rho_{2} \cos \alpha_{2}-r_{j} \phi\right) \sin \phi \\
& +\left(l_{2} \cos \alpha_{2}-h_{a 1}^{*} m+r_{j}\right) \cos \phi, \\
\phi= & \frac{\left(l_{2}+\rho_{2} \cos \alpha_{2} \sin \alpha_{2}-h_{a 1}^{*} m \cos \alpha_{2}\right)}{\left(r_{j} \sin \alpha_{2}\right)}, \\
0 \leq & l_{2} \leq \frac{2 h_{a 1}^{*} m}{\cos \alpha_{2}} .
\end{aligned}
$$


(iii) Coast side flank gear fillet curve is

$$
\begin{aligned}
x_{2}= & \left(-\rho_{1} \sin \theta_{1}-r_{j} \phi\right) \cos \phi \\
& +\left(-\rho_{1}\left(\cos \theta_{1}-\sin \alpha_{1}\right)-h_{a 1}^{*} m+r_{j}\right) \sin \phi, \\
y_{2}= & \left(\rho_{1} \sin \theta_{1}+r_{j} \phi\right) \sin \phi \\
& +\left(-\rho_{1}\left(\cos \theta_{1}-\sin \alpha_{1}\right)-h_{a 1}^{*} m+r_{j}\right) \cos \phi, \\
\phi= & \frac{\left(\rho_{1} \sin \alpha_{1} \sin \theta_{1}-h_{a 1}^{*} m \sin \theta_{1}\right)}{\left(r_{j} \sin \theta_{1}\right)} \\
0 \leq & \theta_{1} \leq \frac{\pi}{2}-\alpha_{1} .
\end{aligned}
$$

(iv) Driving side flank gear fillet curve is

$$
\begin{aligned}
x_{2}= & \left(\rho_{2} \sin \theta_{2}-r_{j} \phi\right) \cos \phi \\
& +\left(-\rho_{2}\left(\cos \theta_{2}-\sin \alpha_{2}\right)-h_{a 1}^{*} m+r_{j}\right) \sin \phi, \\
y_{2}= & -\left(\rho_{2} \sin \theta_{2}-r_{j} \phi\right) \sin \phi \\
& +\left(-\rho_{2}\left(\cos \theta_{2}-\sin \alpha_{2}\right)-h_{a 1}^{*} m+r_{j}\right) \cos \phi, \\
\phi= & -\frac{\left(\rho_{2} \sin \alpha_{2} \sin \theta_{2}-h_{a 1}^{*} m \sin \theta_{2}\right)}{\left(r_{j} \sin \theta_{2}\right)} \\
0 \leq & \theta_{2} \leq \frac{\pi}{2}-\alpha_{2} .
\end{aligned}
$$

When the modification is taken into consideration, the modified profile of driving side can be derived as follows.

In Figure 2, the meshing process can be described by (33), according to (10) and (22)-(23):

$$
-y_{1} \cos \alpha_{2}+x_{1} \sin \alpha_{2}-r_{j} \phi \sin \alpha_{2}=0
$$

From (10) and (33), we can deduce the gear profile equation of profile $B F$ :

$$
\begin{aligned}
x_{2}= & \left(l_{2} \sin \alpha_{2}+\rho_{2} \cos \alpha_{2}-r_{j} \phi\right) \cos \phi \\
& +\left(l_{2} \cos \alpha_{2}-h_{a 1}^{*} m+r_{j}\right) \sin \phi, \\
y_{2}= & -\left(l_{2} \sin \alpha_{2}+\rho_{2} \cos \alpha_{2}-r_{j} \phi\right) \sin \phi \\
& +\left(l_{2} \cos \alpha_{2}-h_{a 1}^{*} m+r_{j}\right) \cos \phi, \\
\phi= & \frac{\left(l_{2}+\rho_{2} \cos \alpha_{2} \sin \alpha_{2}-h_{a 1}^{*} m \cos \alpha_{2}\right)}{\left(r_{j} \sin \alpha_{2}\right)},
\end{aligned}
$$

where $0 \leq l_{2} \leq\left(2 h_{a 1}^{*} m-f_{2}^{*} m\right) / \cos \alpha_{2}$.

Similarly, the deduced meshing equation of profile $F C$ is

$$
-y_{1} \cos \alpha_{3}+x_{1} \sin \alpha_{3}-r_{j} \phi \sin \alpha_{3}=0
$$

The corresponding gear profiles satisfy the following equations:

$$
\begin{aligned}
x_{2}= & \left(l_{3} \sin \alpha_{3}+\rho_{2} \cos \alpha_{2}+\frac{h_{a 1}^{*} m}{\sin \alpha_{2}}-r_{j} \phi\right) \cos \phi \\
& +\left(l_{3} \cos \alpha_{3}+h_{a 1}^{*} m-f_{2}^{*} m+r_{j}\right) \sin \phi, \\
y_{2}= & -\left(l_{3} \sin \alpha_{3}+\rho_{2} \cos \alpha_{2}+\frac{h_{a 1}^{*} m}{\sin \alpha_{2}}-r_{j} \phi\right) \sin \phi \\
& +\left(l_{3} \cos \alpha_{3}+h_{a 1}^{*} m-f_{2}^{*} m+r_{j}\right) \cos \phi, \\
\phi= & \left(l_{3}+h_{a 1}^{*} m \cos \alpha_{3}-f_{2}^{*} m \cos \alpha_{3}\right. \\
& \left.+\rho_{2} \cos \alpha_{2} \sin \alpha_{3}+\frac{h_{a 1}^{*} m}{\sin \alpha_{2}} \sin \alpha_{3}\right) \\
& \times\left(r_{j} \sin \alpha_{3}\right)^{-1},
\end{aligned}
$$

where $0 \leq l_{3} \leq\left(h_{a 1}^{*} m-f_{2}^{*} m\right) / \cos \alpha_{3}$.

3.4. Simulation of Meshing and Contact. The gear profile with and without modification was generated according to the derived equations in Section 3.3, and the corresponding finite element models were also established for subsequent numerical simulation.

The solid models are constructed with the following design parameters. The number of the teeth $Z_{1}=Z_{2}=19$, normal module $m=2.87 \mathrm{~mm}$, face width $b=16 \mathrm{~mm}$, normal pressure angle of coast side flank $\alpha_{1}=20^{\circ}$, normal pressure angle of driving side flank $\alpha_{2}=22.69^{\circ}$, addendum coefficient $h_{a 1}^{*}=1.002$, and tip clearance coefficient $c_{1}^{*}=0.364$. The solid model was discretized with 8 -node hexahedron isoparametric elements. The material was $20 \mathrm{CrMnTi}$ steel with the properties of Young's modulus $E=2.07 e 11 \mathrm{~Pa}$ and Poisson's ratio $\mu=0.25$. The motor power $P=16.41 \mathrm{kw}$, the rated speed $n_{1}$ of driving gear was $3000 \mathrm{r} / \mathrm{min}$, and the applied torque $T=52.25 \mathrm{~N} \cdot \mathrm{m}$ according to the equation $T=60 P /\left(2 \pi n_{1}\right)$.

The considerations for the finite element models are as follows.

(1) The 3D models are adopted due to the differences of tooth surface contact stress along the tooth width direction. Since the overlap ratio of gear pair is 1.463, it is suitable to have the solid model with five gear teeth and inner ring. The simplification is sufficient and highly efficient for the simulation. The two-tooth geometric model is shown in Figure 5(a).

(2) Gear meshing process is a dynamic problem that the meshing position changes with the change of time. So dynamic meshing simulation can be discrete into a series of quasistatic processes. After establishing the corresponding quasistatic mathematical model, using the existing computer technology fulfills the iterative calculation repeatedly to get suitable results. Finite element models of the gear drive can be automatically 


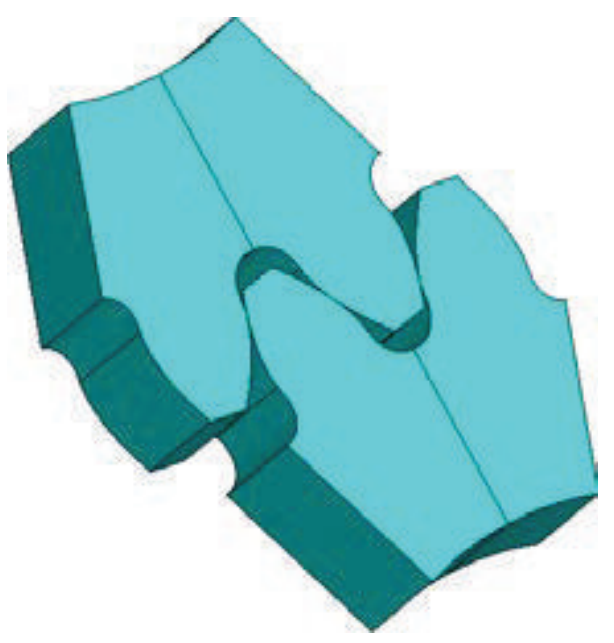

(a)

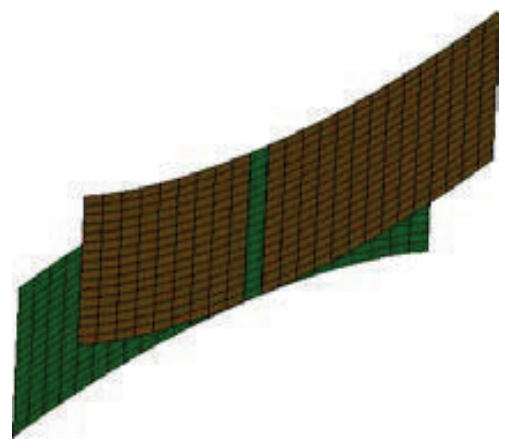

(c)

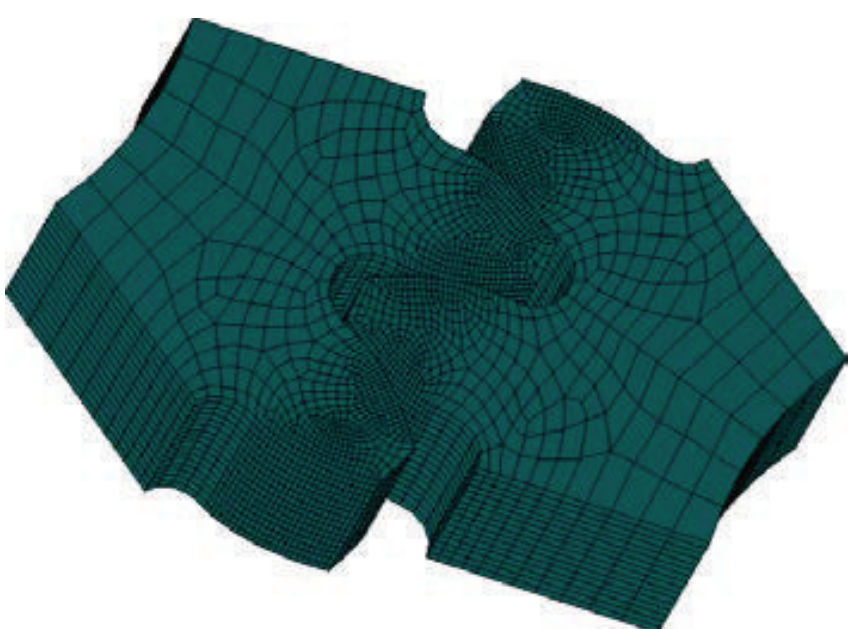

(b)

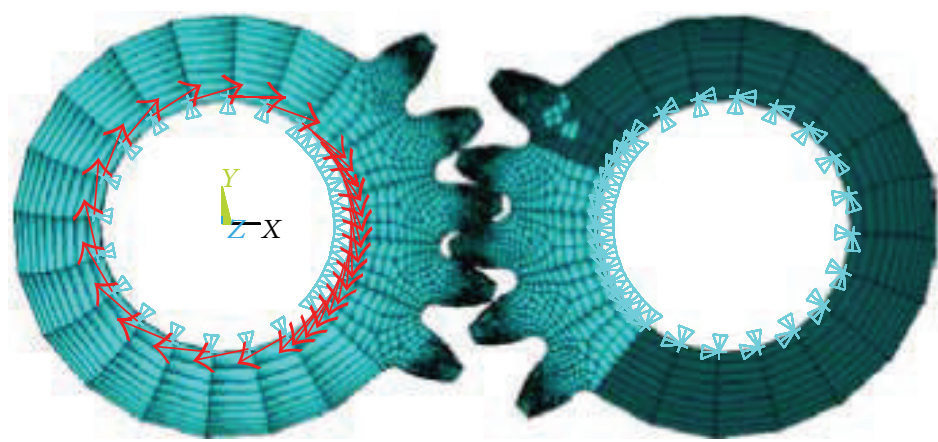

(d)

Figure 5: Two teeth gear models for simulation: (a) the solid model, (b) the finite element model, (c) contact pair, and (d) the whole model with boundary conditions and applied force.

obtained for any meshing position. Through rotating the gear drive, we can achieve the simulation in the whole meshing cycle.

(3) The gear solid model was discretized with 8-node hexahedron isoparametric elements, as shown in Figure 5(b).

(4) The tooth contact is performed by contact elements. A contact pair consists of a target surface and a contact surface. One contact pair is shown in Figure 5(c).

(5) Boundary conditions were imposed automatically in each cylindrical coordinate system. The whole five teeth mating gear finite element models are shown in Figure 5(d).

(6) Nodes of the inner rim of driven gear were fixed by restricting all degrees of freedom; nodes of the inner rim of driving gear are fixed by restricting the radial and axial degree of freedom and releasing the rotational degree of freedom; the transmission torque was exerted to each node in the form of circumferential force. The relationship between the number of nodes in the driving gear rim $n_{\text {number }}$ and the radius of rim $r_{\text {rim }}$ meets the equation

$$
F=\frac{T}{n_{\text {number }} \times r_{\text {rim }}} .
$$

Assumption of load distribution in the contact area is not required since the contact algorithm of the general computer program is used to get the contact area and stresses by application of the torque to the driving gear while the driven gear is considered at rest. Both finite element models of driving and driven gears are rotated to simulate whole meshing cycle, and nonlinear contact analysis was accomplished by the contact algorithm in the finite element program.

Through the numerical simulation, we can predict the characteristic of the gear drive comprehensively and can reveal the principle of gear mating in the design process.

\section{Calculation Results and Discussions}

The purposes of modification are to improve meshing performance and to realize load distribution balance. The two aspects can be evaluated by transmission errors and load sharing ratio. 
The parameter $f$ (Figure 3) was defined as the modified ratio,

$$
f=\frac{f_{2}^{*}}{h_{a 1}^{*}}=\frac{H}{H_{0}} .
$$

The parameter $\Delta \alpha$ was defined as the modified angle meeting

$$
\Delta \alpha=\alpha_{3}-\alpha_{2} .
$$

The pitch point $P_{j}$ where the gears began to mate with each other was defined as the valid starting point. The driven gear rotated counter-clockwise was defined as the positive direction, and the clockwise direction was chosen as the negative direction.

The theoretic angle at the start of active profile (SAP) is $14.65^{\circ}$, and theoretic angle at the end of active profile (EAP) is $-14.65^{\circ}$ according to the formula [26]. Therefore the actual mating angle of one gear tooth should be within the range of $0^{\circ}$ to $29.29186^{\circ}$. The theoretic angles of the lowest point of single tooth contact (LPSTC) and the highest point for single tooth contact (HPSTC) are $4.3^{\circ}$ and $-4.3^{\circ}$ calculated by formula, respectively $[2,26]$. The investigators chose the rotation angles of symmetric spur gear pairs ranging from $15^{\circ}$ to $-16.5^{\circ}$ with an interval of $0.5^{\circ}$.

4.1. Influence of the Transmission Errors. Transmission error (TE) is one of the most important factors causing gear noise and vibration. TE refers to the difference between the displacements of gears in reality and those in theory. TE is calculated as the relative displacement at the pitch point in the line of action between the two engaged gears, using small angle approximations for any relative rotations as shown in

$$
\mathrm{TE}=u_{2}-u_{1},
$$

where $u_{2}$ and $u_{1}$ are the displacements of engaged gears at the pitch point in the line of action. The resulting transmission error is specified as a distance. The displacement of each gear can be obtained by the simulation results.

4.1.1. The Transmission Errors under Different Relief Lengths. When the torque $(T=52.25 \mathrm{~N} \cdot \mathrm{m})$ was applied, the modified angle $\Delta \alpha=0.5^{\circ}$, and the modified ratio values $f$ were $1 / 3,1 / 2$, $2 / 3$, and 1 . The TE curves of driven gear in a meshing cycle under different relief lengths are shown in Figure 6. TE peak amplitudes and percentage increments of double tooth meshing area compared with single tooth meshing area for the unmodified and modified gears under different relief lengths are given in Table 1. Through analysis based on Figure 6, the following results can be drawn.

(1) Mating zones $A$ and $C$ are the single tooth meshing areas, and mating zone $B$ is double tooth meshing area. In the unmodified model, there exist convex line in zone $B$ and concave lines in zones $A$ and $C$. The gear has lower mating stiffness in zone $B$; therefore the amplitude of TE in zone $B$ is greater than that in zones $A$ and $C$. The lowest point in zones $A$ and $C$ is

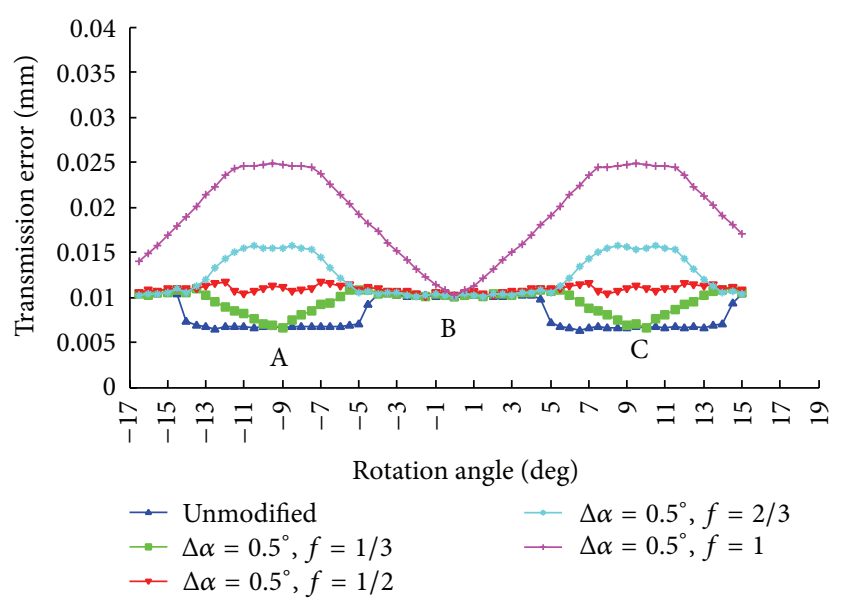

FIgURE 6: The transmission errors for driven gear under different relief lengths, $\Delta \alpha=0.5^{\circ}$.

called the negative TE peak point. The TE amplitude in zones $A$ and $C$ is $39.782 \%$, lower than in zone $B$ (Table 1).

(2) Compared with the unmodified model, the relief length is a critical factor for determining TE curve shape. When $f=1 / 3$, zone $B$ has wider space. Zones $A$ and $C$ have same concave shape as the unmodified model but have a sharp point at the lowest position. When $f=1 / 2$, zone $B$ also has wider range than the unmodified model. The curves in zones $A$ and $C$ are rough and uneven. When $f=2 / 3$, there is obvious difference between single tooth meshing and double tooth meshing areas. The curves in the zones $A$ and $C$ also change from concave to convex shape, and its range decreases with increasing zone $B$. When $f=1$, the relief starts from the pitch point, so zone $B$ changes from a line to a point. The curve in zones $A$ and $C$ changes from concave to convex shape dramatically.

(3) The relief length has great effect on the TE amplitude, especially the double tooth meshing areas. When $f=1 / 3$, the curve in zones $A$ and $C$ has sharper negative peak but even amplitude compared with the unmodified model. The negative peak amplitude in zones $A$ and $C$ is $6.57885 \mu \mathrm{m}, 40.0133 \%$ lower than the peak amplitude in zone $B$. When $f=1 / 2$, the negative peak amplitude in zones $A$ and $C$ is $11.64246 \mu \mathrm{m}$, $16.07 \%$ higher than the peak amplitude in zone $B$. When $f=2 / 3$, the peak amplitude in zones $A$ and $C$ is $15.71421 \mu \mathrm{m}$, which is $55.98 \%$ higher than the peak amplitude in zone $B$. When $f=1$, the negative peak amplitude in zones $A$ and $C$ is $24.89898 \mu \mathrm{m}$, $142.6177 \%$ higher than the peak amplitude in zone $B$ (Table 1).

(4) The TE peak amplitude of modified model in zone $B$ changes little when compared with the unmodified one with the increasing modified factor $f$. The TE peak amplitude of the modified model in zones $A$ 
TABLE 1: TE peak amplitudes and percentage increments in double tooth meshing area when compared with single tooth meshing area of the unmodified and modified gears under different relief lengths.

\begin{tabular}{lccc}
\hline Modification dimensions & $\begin{array}{r}\text { TE peak amplitude in zones A } \\
\text { and C }(\mu \mathrm{m})\end{array}$ & $\begin{array}{c}\text { TE peak amplitude in zone B } \\
(\mu \mathrm{m})\end{array}$ & $\begin{array}{c}\text { Percentage of TE peak } \\
\text { increment }(\%)\end{array}$ \\
\hline Unmodified gear & 6.3684 & 10.57557 & -39.782 \\
$\Delta \alpha=0.5^{\circ}, f=1 / 3$ & 6.57885 & 10.96719 & -40.0133 \\
$\Delta \alpha=0.5^{\circ}, f=1 / 2$ & 11.64246 & 10.03023 & 16.07371 \\
$\Delta \alpha=0.5^{\circ}, f=2 / 3$ & 15.71421 & 10.07415 & 55.98547 \\
$\Delta \alpha=0.5^{\circ}, f=1$ & 24.89898 & 10.26264 & 142.6177 \\
\hline
\end{tabular}

and $C$ increases as the relief factor $f$ increases. It was found that the relief factor $f=1 / 2$ is relatively optimal to make the curve of TE level and smooth. When $f=1 / 3$ or $f=2 / 3$, the relief length is sufficient, and when $f=1$, the relief length is excessive.

4.1.2. The Transmission Errors under Different Relief Pressure Angles. When the applied torque was $52.25 \mathrm{~N} \cdot \mathrm{m}$, the modified angle values $\Delta \alpha$ were $0.3^{\circ}, 0.5^{\circ}$, or $0.7^{\circ}$, and the modified ratio values $f$ were $1 / 3,1 / 2,2 / 3$, or 1 . The TE curves of driven gear in a meshing cycle under different relief pressure angles are shown in Figure 7. TE peak amplitudes of modified gears under different relief lengths are given in Table 2. Through the analysis based on Figure 7, the following results can be obtained.

(1) The relief pressure angle has great effect on the variation range of the $\mathrm{TE}$ when the modified ratio is a constant. As the $\Delta \alpha$ increases, the value of $\mathrm{TE}$ increases.

(2) When $f=1 / 3$, the maximum value of TE in single tooth meshing area increases with increasing $\Delta \alpha$. The negative peak amplitudes in double tooth meshing area change very little (Table 2 ). The width of double tooth meshing areas becomes narrower with increasing $\Delta \alpha$. When $f=1 / 2$, the shape of curve in double tooth meshing areas changes from concave with two peaks into convex with one peak. The peak amplitudes increase with increasing $\Delta \alpha$. When $f=$ $2 / 3$ or $f=1$, the TE values increase with increasing $\Delta \alpha$.

(3) The modification length is the main factor that determines the shape of the transmission error curve. Appropriate modification length can make the gear transmission error curve in the process of alternating single and double teeth smooth, thereby reducing the meshing dynamics. Modification angle is the main factor influencing the peak transmission error. Suitable pressure angle can make the transmission error fluctuation decrease. In present study, it was found that the TE curve would be level and smooth when $f=1 / 2, \alpha=0.5^{\circ}$ for the assumed torque.

\subsection{Influence of the Contact Force}

4.2.1. The Load Sharing Ratio under Different Relief Lengths. Due to the material having flexibility, the deformed teeth can rotate, bend, and shear, and the tooth flanks have been flattened at the contact points. In this situation, the load varies outside the normal contact path of asymmetric spur gears. The curves of tooth load sharing ratio can clearly show the complex variation from the tooth running in, to running out of contact. The circumference force and radial force of meshing gear satisfy the following equations, respectively:

$$
\begin{aligned}
& F_{t}=\frac{T}{r_{j}} \\
& F_{r}=F_{t} \tan \alpha
\end{aligned}
$$

The theoretic total meshing force is given by

$$
F_{n}=\sqrt{F_{r}^{2}+F_{t}^{2}}
$$

where $r_{j}=m z / 2$. Then the total meshing force $F_{n}$ can be determined to be $2075 \mathrm{~N}$ by substituting the involved parameters. A single gear meshing force $F_{\text {sn }}$ can be obtained by simulation results. The load sharing ratio is given by

$$
K=\frac{F_{\text {sn }}}{F_{n}} .
$$

Taking one gear tooth for consideration in the whole meshing cycle, distribution of the contact force under different relief lengths is given in Figure 8. Through analysis based on Figure 8, the following results can be obtained.

(1) The load sharing ratio is $100 \%$ in single tooth meshing area and $35 \%-46 \%$ in double tooth meshing areas of unmodified model. There is a sharp drop at the LPSTC and the HPSTC.

(2) The load sharing ratio in double tooth meshing areas is $0-100 \%$. The slopes of the line increase and the space becomes narrower with the increasing relief length in double tooth meshing areas.

(3) When the rotation angles are within the range of $15^{\circ}-9.6^{\circ}$ and $-9.5^{\circ}-15^{\circ}$, the change amplitude of load sharing ratio decreases as $f$ increases. When the rotation angle is in the range of $9.6^{\circ}-4^{\circ}$ and from $-4^{\circ}$ to $9.6^{\circ}$, the change amplitude of load sharing ratio increases as $f$ increases. 


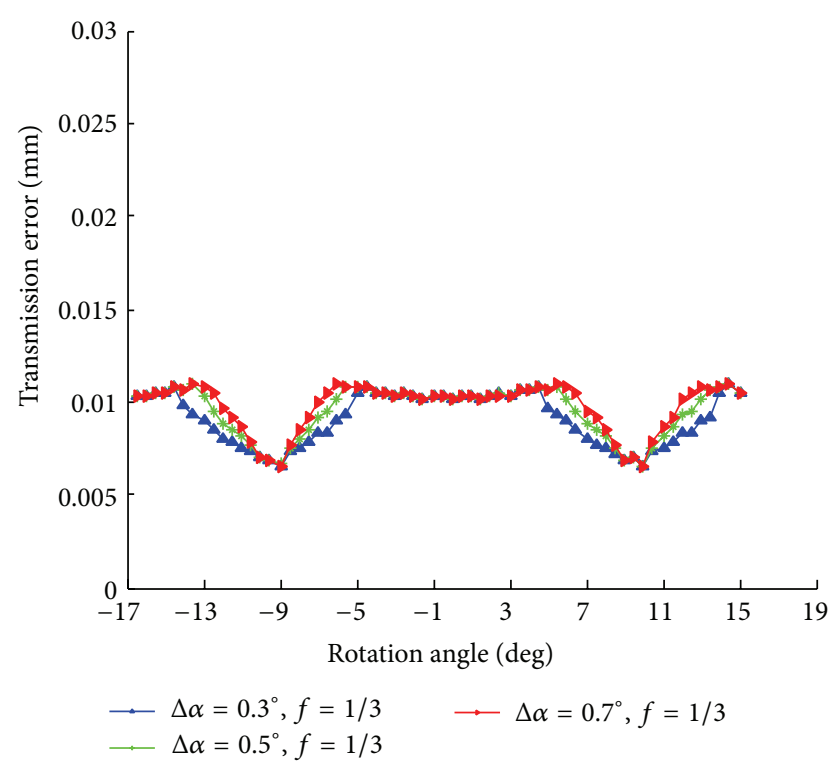

(a)

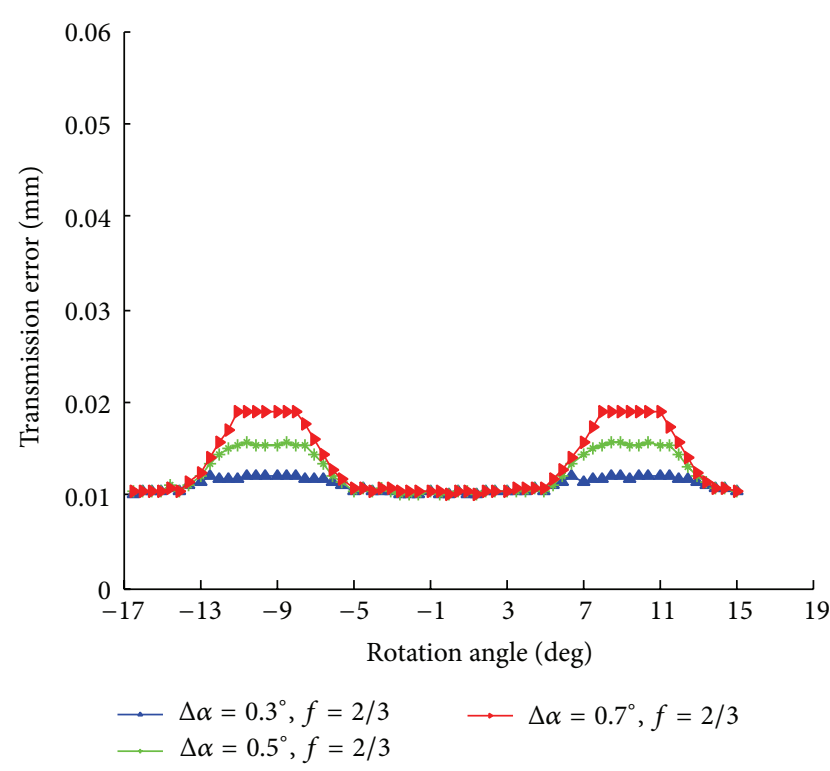

(c)

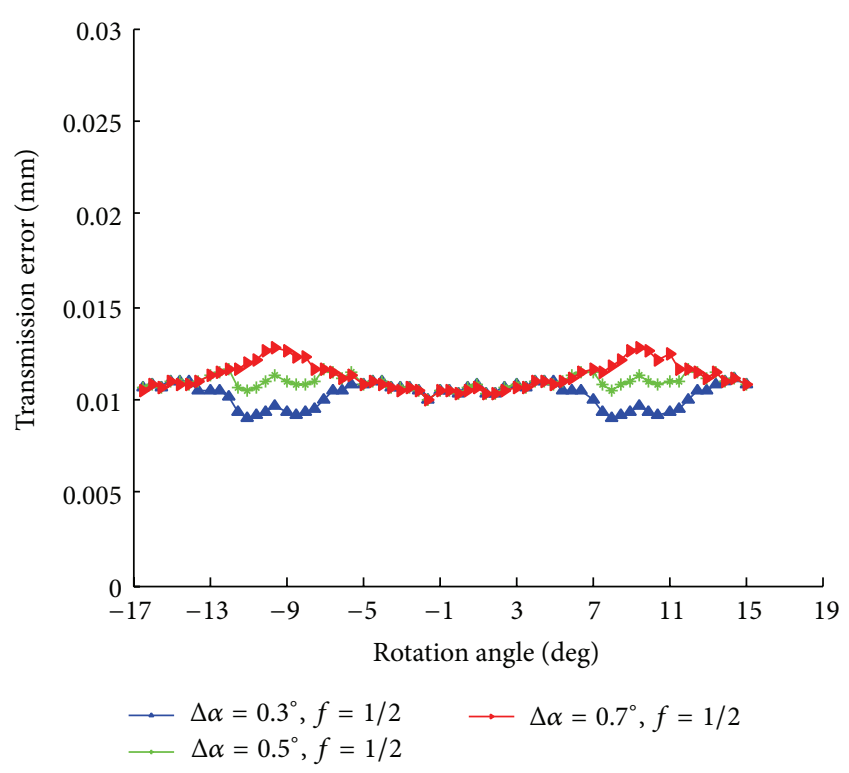

(b)

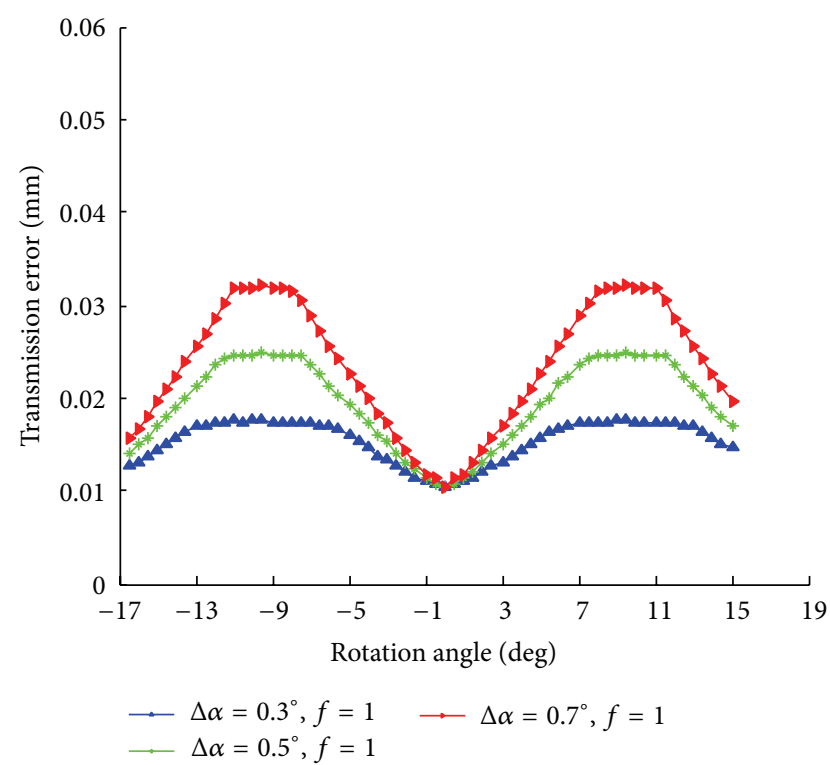

(d)

Figure 7: The transmission errors for driven gear under relief pressure angles: (a) $f=1 / 3$, (b) $f=1 / 2$, (c) $f=2 / 3$, and (d) $f=1$.

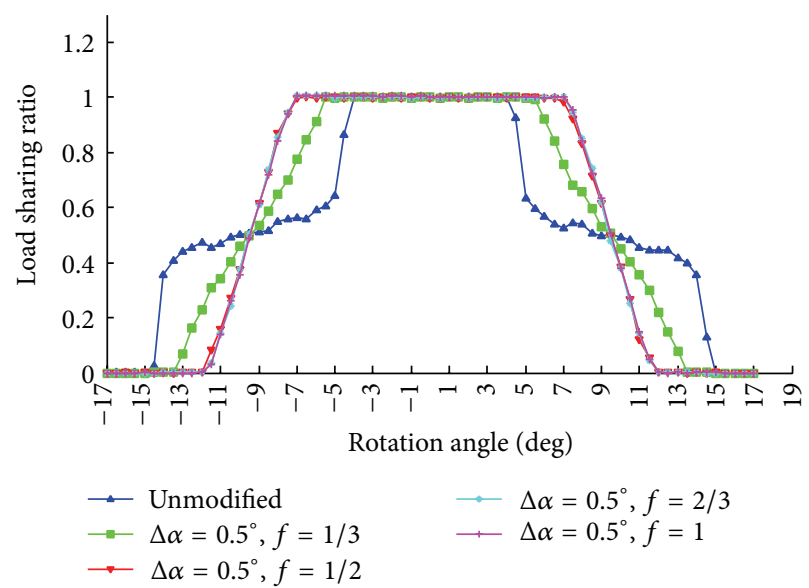

FIGURE 8: The load sharing ratio against different relief lengths input at $\Delta \alpha=0.5$. 


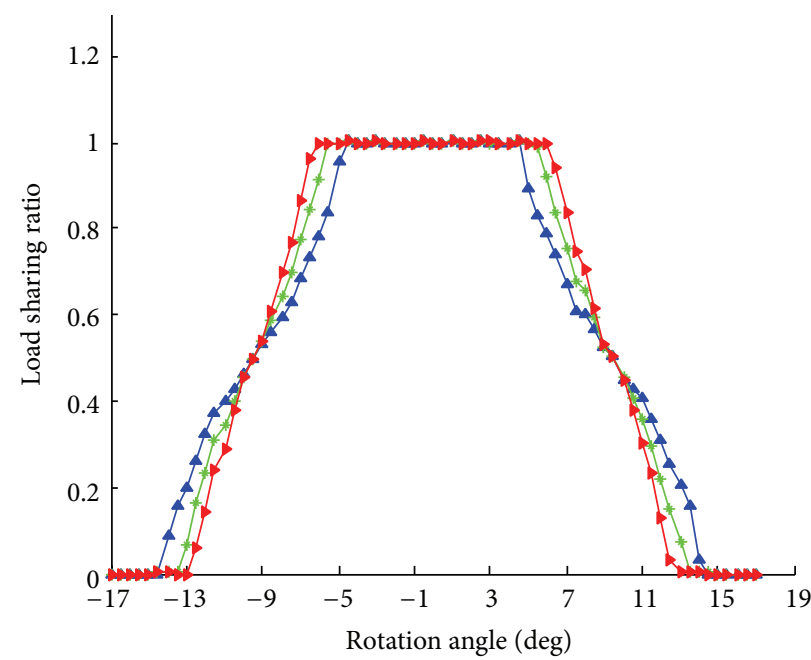

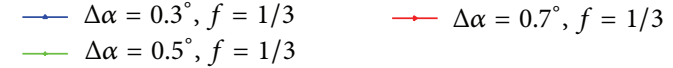

(a)

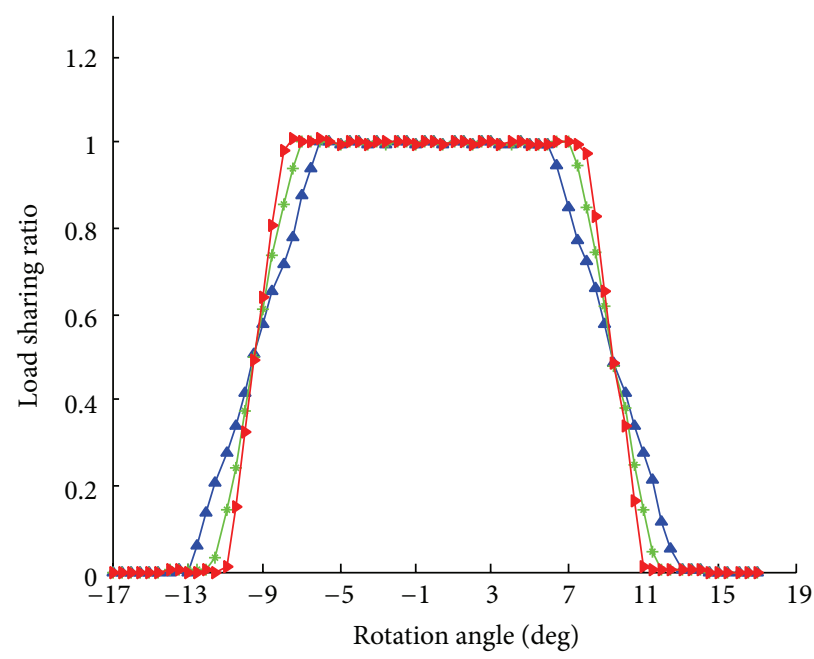

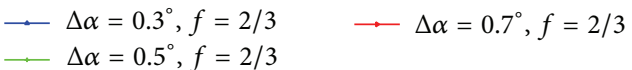

(c)

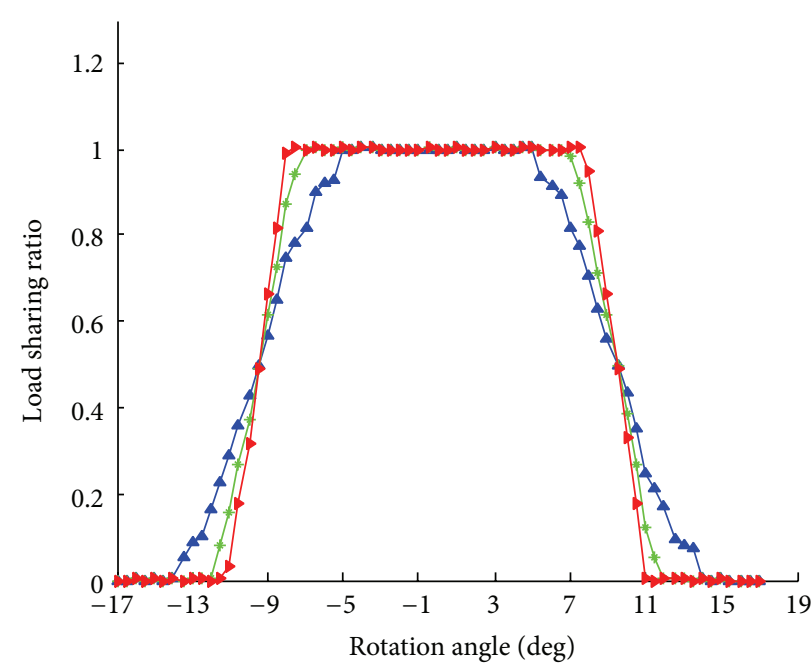

$\because \Delta \alpha=0.3^{\circ}, f=1 / 2 \quad \longrightarrow \Delta \alpha=0.7^{\circ}, f=1 / 2$

$\longrightarrow \Delta \alpha=0.5^{\circ}, f=1 / 2$

(b)

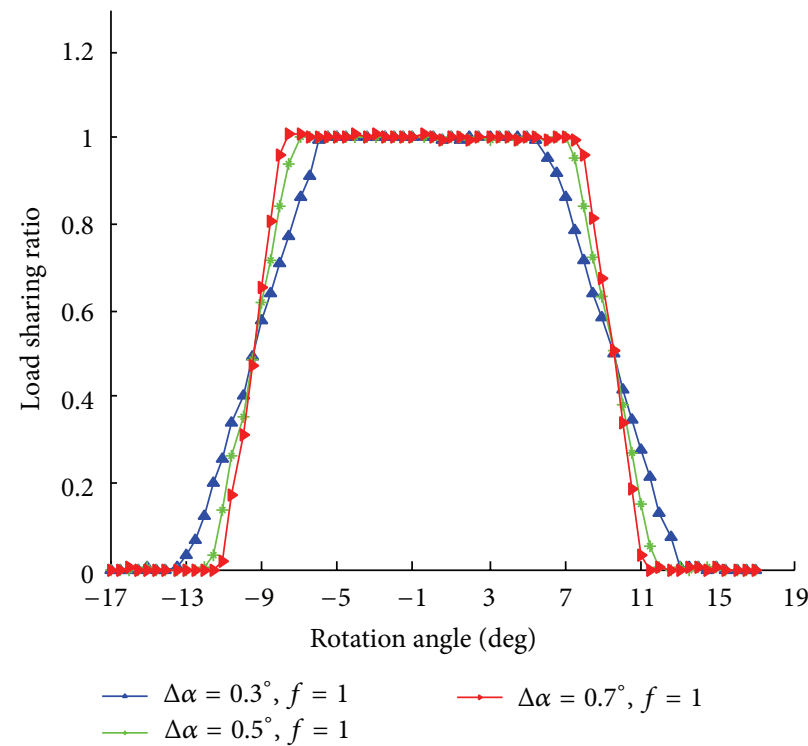

(d)

FIGURE 9: The load sharing ratio against different relief lengths and relief angles input: (a) $f=1 / 3$, (b) $f=1 / 2$, (c) $f=2 / 3$, and (d) $f=1$.

TABLE 2: TE peak amplitudes of the modified gears under different relief lengths $(\mu \mathrm{m})$.

\begin{tabular}{|c|c|c|c|c|c|c|}
\hline & \multicolumn{3}{|c|}{ Single tooth meshing area } & \multicolumn{3}{|c|}{ Double tooth meshing area } \\
\hline & $\Delta \alpha=0.3^{\circ}$ & $\Delta \alpha=0.5^{\circ}$ & $\Delta \alpha=0.7^{\circ}$ & $\Delta \alpha=0.3^{\circ}$ & $\Delta \alpha=0.5^{\circ}$ & $\Delta \alpha=0.7^{\circ}$ \\
\hline$f=1 / 3$ & 10.91595 & 10.96719 & 10.96902 & 6.54042 & 6.57885 & 6.54591 \\
\hline$f=1 / 2$ & 11.11725 & 11.64246 & 11.6937 & 8.92308 & 10.03023 & 12.78804 \\
\hline$f=2 / 3$ & 10.02108 & 10.07415 & 10.15467 & 12.17865 & 15.71421 & 19.10337 \\
\hline$f=1$ & 10.23519 & 10.26264 & 10.48041 & 17.57715 & 24.89898 & 32.1714 \\
\hline
\end{tabular}


4.2.2. The Contact Force under Different Relief Pressure Angles. When the applied torque was $52250 \mathrm{Nm}$, the modified angle values $\Delta \alpha$ were $0.3^{\circ}, 0.5^{\circ}$, or $0.7^{\circ}$, and the modified ratio values $f$ were $1 / 3,1 / 2,2 / 3$, or 1 . Through analysis based on Figure 9 , the following results can be obtained.

(1) When the rotation angles are in the range of $15^{\circ}-9.6^{\circ}$ and from $-9.5^{\circ}$ to $15^{\circ}$, the amplitude of load sharing ratio declines as $f$ increases. When the rotation angles are in the range of $9.6^{\circ}-4^{\circ}$ and $-4^{\circ}-9.6^{\circ}$, the change amplitude of load sharing ratio increases as $f$ increases.

(2) The load sharing ratio is $100 \%$ in single tooth meshing area. The slope of the line increases and the space range becomes narrower with the increasing relief length in double tooth meshing areas.

(3) Length of modification and modification angle determines the shape of the curve of load distribution and proportion. In the analysis of load distribution, $f=$ $1 / 2, \alpha=0.5^{\circ}$ is reasonable.

\section{Conclusions}

Based on the research performed, the following conclusions can be drawn.

(1) A design method for the geometric profile of asymmetric spur gear was proposed, in which the geometric profile of the gear can be obtained directly according to the rack-cutter profile in the design process. The geometric equations of rack-cutter were conducted, and the corresponding equations of generated gear were deduced based on the conjugated theory.

(2) A design method for the modification of asymmetric spur gear was proposed, in which the modification of the gear can be obtained via the pressure angle modification of the rack-cutter. The geometric equations of the modified driving side of rack-cutter were conducted, and the corresponding equations of the generated gear were deduced based on the conjugated theory.

(3) The designed and modified gear models can be adopted to carry out the subsequent mating analysis. The research results indicated that the involute modification of the generated gear contributed to better transmission performance.

\section{Nomenclature}

$m: \quad$ Metric module, $\mathrm{mm}$

$z: \quad$ Tooth number

$\alpha_{i}(i=1,2,3)$ : Pressure angle for asymmetric spur gear drive: $(i=1)$ for coast side profile, $(i=2)$ for driving side profile, $(i=3)$ for modified driving side profile

$\rho_{i}(i=1,2): \quad$ Radius of rack-cutter fillet: $(i=1)$ for coast side profile, $(i=2)$ for driving side profile

$h_{a 1}^{*}: \quad$ Addendum coefficient

$c_{1}^{*}$ : $\quad$ Tip clearance coefficient
E: $\quad$ End point of coast side straight line

D: $\quad$ Start point of coast side straight line

$C$ : $\quad$ End point of driving side straight line

$B: \quad$ Start point of driving side straight line

A: $\quad$ Bottom point of rack-cutter fillet curve

$O_{i}(i=c, d): \quad$ Center point of rack-cutter fillet: $(i=c)$ for coast side profile, $(i=d)$ for driving side profile

$Q_{1}, Q_{2}, Q_{5}$ : Arbitrary point in straight line $D E, B C, F C$

$Q_{3}, Q_{4}$ : Arbitrary point in rack-cutter fillet curve $A D, A B$

$l_{1}, l_{2}, l_{3}$ : Length of straight line $D Q_{1}, B Q_{2}, F Q_{5}$

$\theta_{1}, \theta_{2}: \quad$ Angle of ${ }_{A} O_{d} Q_{3}, \sqrt{A} O_{c} Q_{4}$

$f_{2}^{*}: \quad$ Modified coefficient

$f: \quad$ Modified ratio

$\Delta \alpha: \quad$ Modified angle

$S_{i}(i=1,2, j)$ : Coordinate systems: $(i=1)$ for rack-cutter, $(i=2)$ for conjugate gear, $(i=j)$ for fixed frame

$r_{j}$ : Radius of pitch cylinder of gear.

\section{Conflict of Interests}

The authors declare that there is no conflict of interests regarding the publication of this paper.

\section{Acknowledgments}

The authors would like to thank the Natural Science Foundation of China (no. 51105287) and the Key Research and Development Project of New Product and New Technology of Hubei Province (no. 2012BAA08003) for the support given to this research.

\section{References}

[1] J. D. Smith, Gear Noise and Vibration, Marcel Dekker, New York, NY, USA, 2003.

[2] F. L. Litvin, Gear Geometry and Applied Theory, Cambridge University Press, Cambridge, UK, 2nd edition, 2004.

[3] F. L. Litvin, Q. Lian, and A. L. Kapelevich, "Asymmetric modified spur gear drives: reduction of noise, localization of contact, simulation of meshing and stress analysis," Computer Methods in Applied Mechanics and Engineering, vol. 188, no. 1, pp. 363-390, 2000.

[4] C. Song, C. Zhu, T. C. Lim, and T. Peng, "Parametric analysis of gear mesh and dynamic response of loaded helical beveloid transmission with small shaft angle," Journal of Mechanical Design, vol. 134, no. 8, Article ID 084501, 2012.

[5] J. Y. Tang, Z. H. Hu, L. J. Wu, and S. Y. Chen, "Effect of static transmission error on dynamic responses of spiral bevel gears," Journal of Central South University, vol. 20, no. 3, pp. 640-647, 2013.

[6] C. Huang, J.-X. Wang, K. Xiao, M. Li, and J.-Y. Li, "Dynamic characteristics analysis and experimental research on a new type planetary gear apparatus with small tooth number difference," Journal of Mechanical Science and Technology, vol. 27, no. 5, pp. 1233-1244, 2013. 
[7] F. L. Litvin, A. Fuentes, I. Gonzalez-Perez, L. Carvenali, K. Kawasaki, and R. F. Handschuh, "Modified involute helical gears: computerized design, simulation of meshing and stress analysis," Computer Methods in Applied Mechanics and Engineering, vol. 192, no. 33-34, pp. 3619-3655, 2003.

[8] M. Faggioni, F. S. Samani, G. Bertacchi, and F. Pellicano, "Dynamic optimization of spur gears," Mechanism and Machine Theory, vol. 46, no. 4, pp. 544-557, 2011.

[9] M. Barbieri, G. Bonori, and F. Pellicano, "Optimum profile modifications of spur gears by means of genetic algorithms," Journal of Sound and Vibration, vol. 331, no. 21, pp. 4825-4829, 2012.

[10] H. Zhang, L. Hua, and X. H. Han, "Computerized design and simulation of meshing of modified double circular-arc helical gears by tooth end relief with helix," Mechanism and Machine Theory, vol. 45, no. 1, pp. 46-64, 2010.

[11] I. Gonzalez-Perez, J. L. Iserte, and A. Fuentes, "Implementation of Hertz theory and validation of a finite element model for stress analysis of gear drives with localized bearing contact," Mechanism and Machine Theory, vol. 46, no. 6, pp. 765-783, 2011.

[12] K. J. Huang and H. W. Su, "Approaches to parametric element constructions and dynamic analyses of spur/helical gears including modifications and undercutting," Finite Elements in Analysis and Design, vol. 46, no. 12, pp. 1106-1113, 2010.

[13] Y. Hu, Y. Shao, Z. Chen, and M. J. Zuo, "Transient meshing performance of gears with different modification coefficients and helical angles using explicit dynamic FEA," Mechanical Systems and Signal Processing, vol. 25, no. 5, pp. 1786-1802, 2011.

[14] J. Wei, W. Sun, and L. Wang, "Effects of flank deviation on load distributions for helical gear," Journal of Mechanical Science and Technology, vol. 25, no. 7, pp. 1781-1789, 2011.

[15] Y.-J. Wu, J.-J. Wang, and Q.-K. Han, "Static/dynamic contact FEA and experimental study for tooth profile modification of helical gears," Journal of Mechanical Science and Technology, vol. 26, no. 5, pp. 1409-1417, 2012.

[16] S. T. Li, "Finite element analyses for contact strength and bending strength of a pair of spur gears with machining errors, assembly errors and tooth modifications," Mechanism and Machine Theory, vol. 42, no. 1, pp. 88-114, 2007.

[17] V. V. Simon, "Influence of tooth modifications on tooth contact in face-hobbed spiral bevel gears," Mechanism and Machine Theory, vol. 46, no. 12, pp. 1980-1998, 2011.

[18] Z. Chen and Y. Shao, "Mesh stiffness calculation of a spur gear pair with tooth profile modification and tooth root crack," Mechanism and Machine Theory, vol. 62, pp. 63-74, 2013.

[19] S. Sankar and M. Nataraj, "Profile modification-a design approach for increasing the tooth strength in spur gear," International Journal of Advanced Manufacturing Technology, vol. 55, no. 1-4, pp. 1-10, 2011.

[20] J. Wang, Y. Wang, and Z. Huo, "Finite element residual stress analysis of planetary gear tooth," Advances in Mechanical Engineering, vol. 2013, Article ID 761957, 12 pages, 2013.

[21] S. Li and A. Kahraman, "A tribo-dynamic model of a spur gear pair," Journal of Sound and Vibration, vol. 332, no. 20, pp. 49634978, 2013.

[22] M. Kolivand and A. Kahraman, "A general approach to locate instantaneous contact lines of gears using surface of roll angle," Journal of Mechanical Design, vol. 133, no. 1, Article ID 014503, 2011.
[23] T. Eritenel and R. G. Parker, "Nonlinear vibration of gears with tooth surface modifications," Journal of Vibration and Acoustics, vol. 135, no. 5, Article ID 051005, 2013.

[24] O. Alipiev, "Geometric design of involute spur gear drives with symmetric and asymmetric teeth using the Realized Potential Method," Mechanism and Machine Theory, vol. 46, no. 1, pp. 1032, 2011.

[25] N. L. Pedersen, "Improving bending stress in spur gears using asymmetric gears and shape optimization," Mechanism and Machine Theory, vol. 45, no. 11, pp. 1707-1720, 2010.

[26] S.-C. Hwang, J.-H. Lee, D.-H. Lee, S.-H. Han, and K.-H. Lee, "Contact stress analysis for a pair of mating gears," Mathematical and Computer Modelling, vol. 57, no. 1-2, pp. 40-49, 2013. 


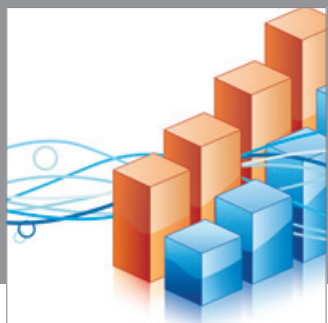

Advances in

Operations Research

mansans

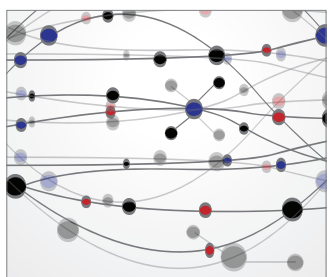

The Scientific World Journal
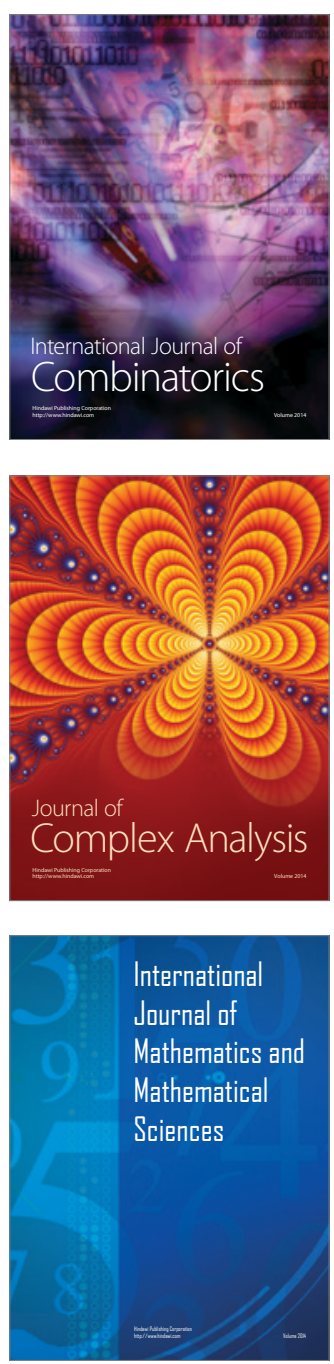
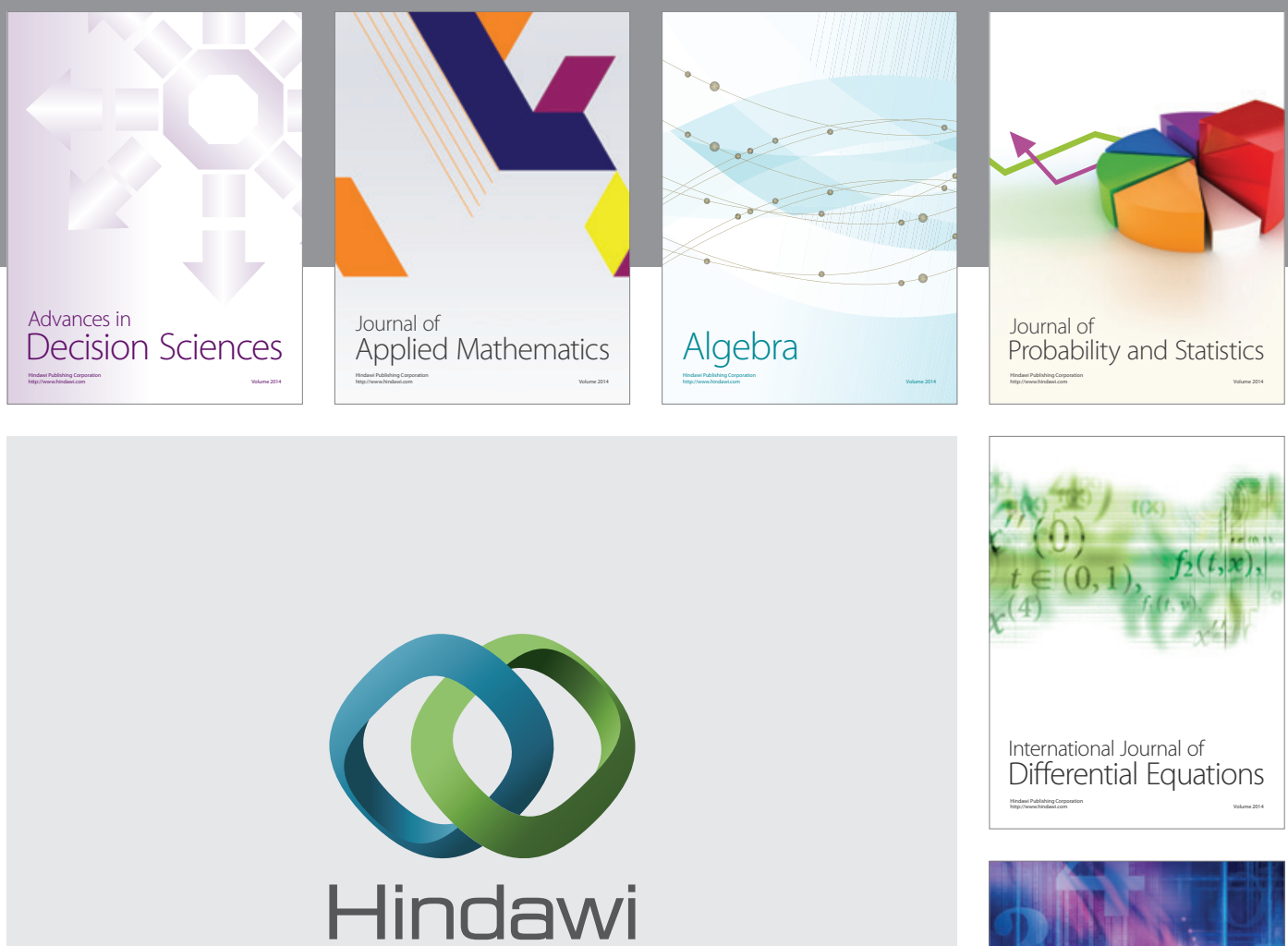

Submit your manuscripts at http://www.hindawi.com
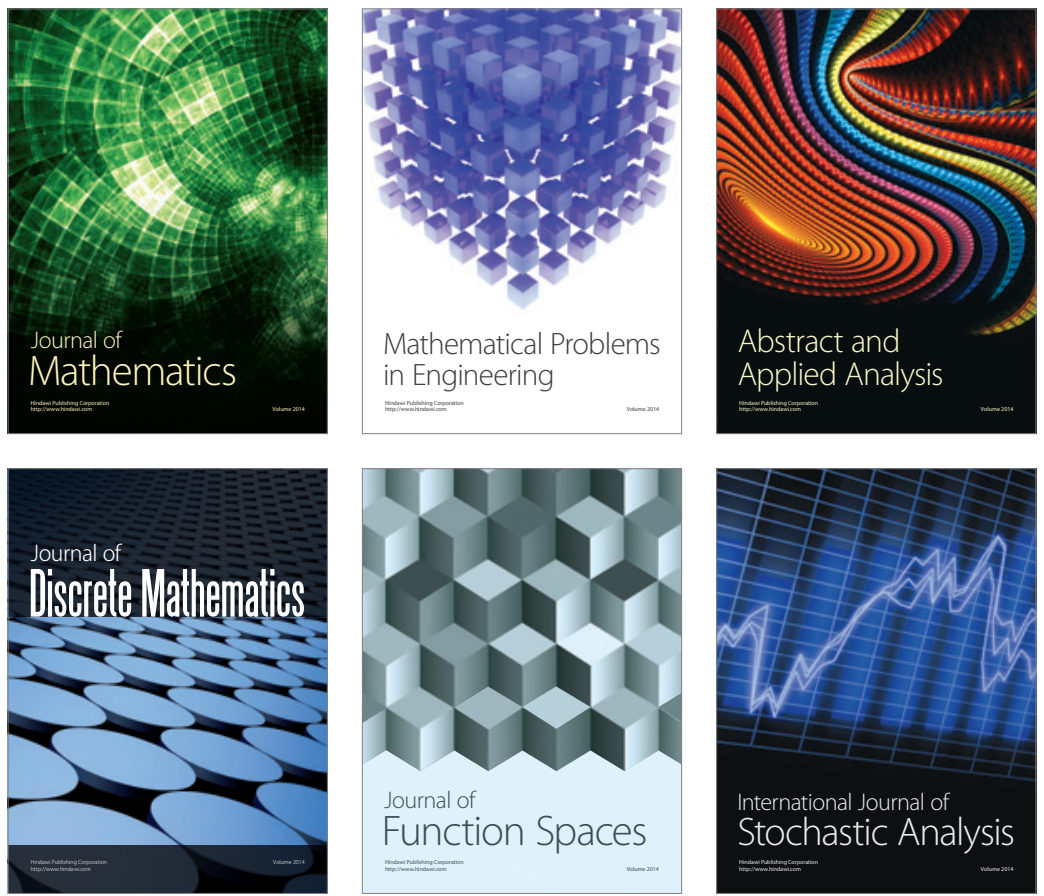

Journal of

Function Spaces

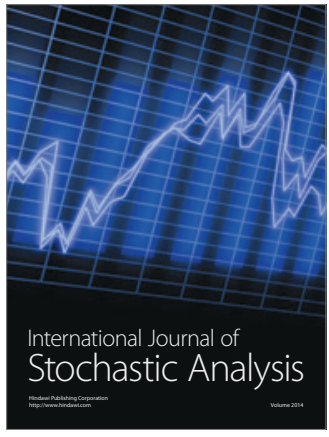

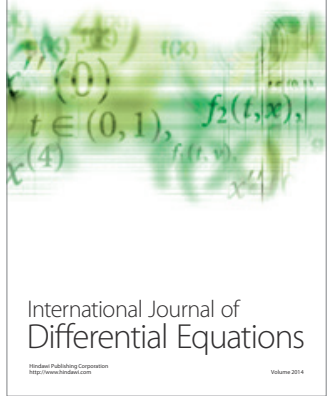
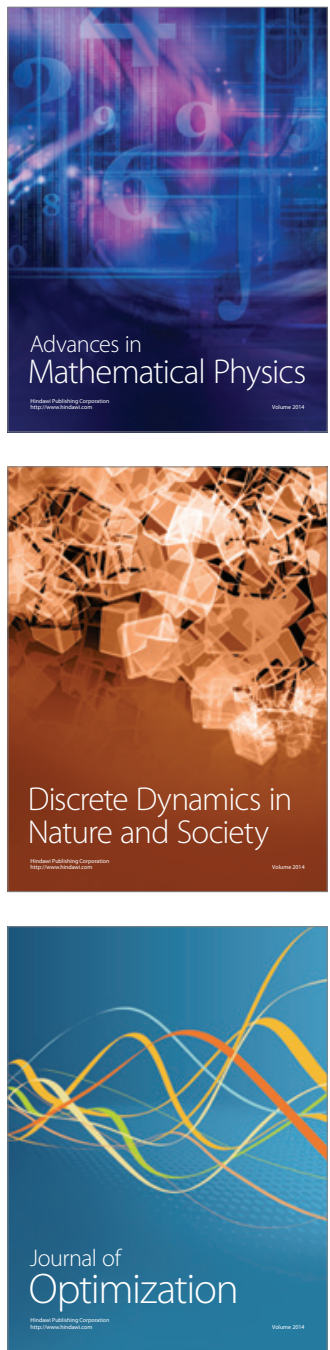